\title{
ТОНКОСТРУКТУРНЫЕ СПЕКТРЫ И КИНЕТИКА ЛЮМИНЕСЦЕНЦИИ ХЛОРОФИЛЛА И ЕГО ПРОИЗВОДНЫХ
}

Дается обзор исследований по тонкоструктурным спектрам хлорофиллоподобных молекул при селективном лазерном возбужденин, а также по кинетическим измерениям, относящимся к этой проблеме.

\section{Введение}

Десяток лет назад были сделаны первые попытки получить тонкоструктурные электронно-колебательные (вибронные) спектры важнейшего фотосинтезирующего соединения - хлорофилла $a$ (Хл $a$ ). Метод Шпольского (т. е. внедрение молекул в $\mathrm{H}$-алкановые матрицы), использованный для получения квазилинейчатых спектров порфиринов при $77 \mathrm{~K}\left[{ }^{1}\right]$, дал обещающие результаты в случае Хл $а$ при $4,2 \mathrm{~K}\left[{ }^{2,3}\right]$, однако спектры оказались плохо воспроизводимыми. Цель этих работ можно сформулировать как доведение спектроскопии хлорофиллоподобных молекул до уровня, достигнутого к этому времени для менее сложных органических молекул. Следует отметить, что незадолго до этого решались некоторые принципиальные вопросы сfтектроскопии твердого тела - наличие фононных крыльев в спектрах растворенных в твердой матрице молекул и природа мультиплетов в спектрах Шпольского $\left[{ }^{4}\right]$.

Новый этап в изучении спектроз хлорофилла начался благодаря применению лазерных источников возбуждения. Природа бесструктурных полос флуоресценции молекул в аморфных системах была разъяснена Р. И. Персоновым с сотрудниками, которые обнаружили яркое проявление узколинейчатой структуры при резонансном лазерном возбуждении на примере молекулы перилена $\left[{ }^{5}\right]$.

Мы наблюдали возникновение тонкой структуры при селективном лазерном возбуждении спектра флуоресценции Хл $a$ при 4,2 K в различных неалкановых растворителях [ $\left.{ }^{6}\right]$. Однако в данном случае интерпретация спектров превращалась сама по себе в трудную задачу из-за сложности изучаемых систем. С целью четкого различения характеристик, присущих самим изучаемым молекулам, и эффектов, возникающих в связи со спецификой способа получения спектров, нами было проведено соответствующее теоретическое рассмотрение [ $\left.{ }^{7}\right]$.

Қак известно, вибронные спектры молекулярной примеси в кристалле состоят из узкой чисто электронной $0-0$-линии, сопровождаемой широким фононным крылом, а также ее повторений по внутримолекулярным колебаниям [ $\left.{ }^{8}\right]$. Для сложных молекул в органических матрицах эта информация часто теряется из-за большого неоднородного уширения. Селективное возбуждение монохроматическим светом частично снимает это уширение $\left[{ }^{5}\right]$, но наблюдаемые параметры по сравнению с установленными теорией однородных спектров значительно изменяются $\left[{ }^{7}\right]$. Так, ширина бесфононной линии (БФЛ) складывается из однородных ширин линий поглощения и флуоресценции. Фононное крыло в спектре излучения содержит три компоненты: 1) истинное крыло, 
2) огибающую большого числа возбуждаемых через фононное крыло БФЛ и 3) сумму их фононных крыльев. В результате относительная интенсивность БФЛ значительно ослабляется.

При возбуждении в области вибронных переходов наиболее ярким эффектом является возникновение $0-0$-мультиплета «псевдолиний». Эти БФЛ отстоят от возбуждающей линии на расстояниях, равных частотам колебаний молекулы в возбужденном электронном состоянии.

Знания этих основных положений теории достаточно для расшифровки структуры спектров флуоресценции и возбуждения. Более детальные теоретические трактовки даны в последующих публикациях, например, в $\left[{ }^{9}\right]$.

В настоящей работе приводится сводка результатов наших исследований по тонкоструктурным спектрам Хл $a$ и его ближайших аналогов, а также по кинетическим измерениям в условиях спектрально селективной регистрации.

\section{Результаты и обсуждение}

При комнатной и азотной температурах спектры поглощения и люминесценции хлорофиллоподобных молекул состоят из сравнительно широких $\left(\approx 300 \mathrm{~cm}^{-1}\right)$ полос. Возбуждение на вибронном спутнике т. н. $Q(0,0)$-полосы поглощения приводит при гелиевой температуре к воз-

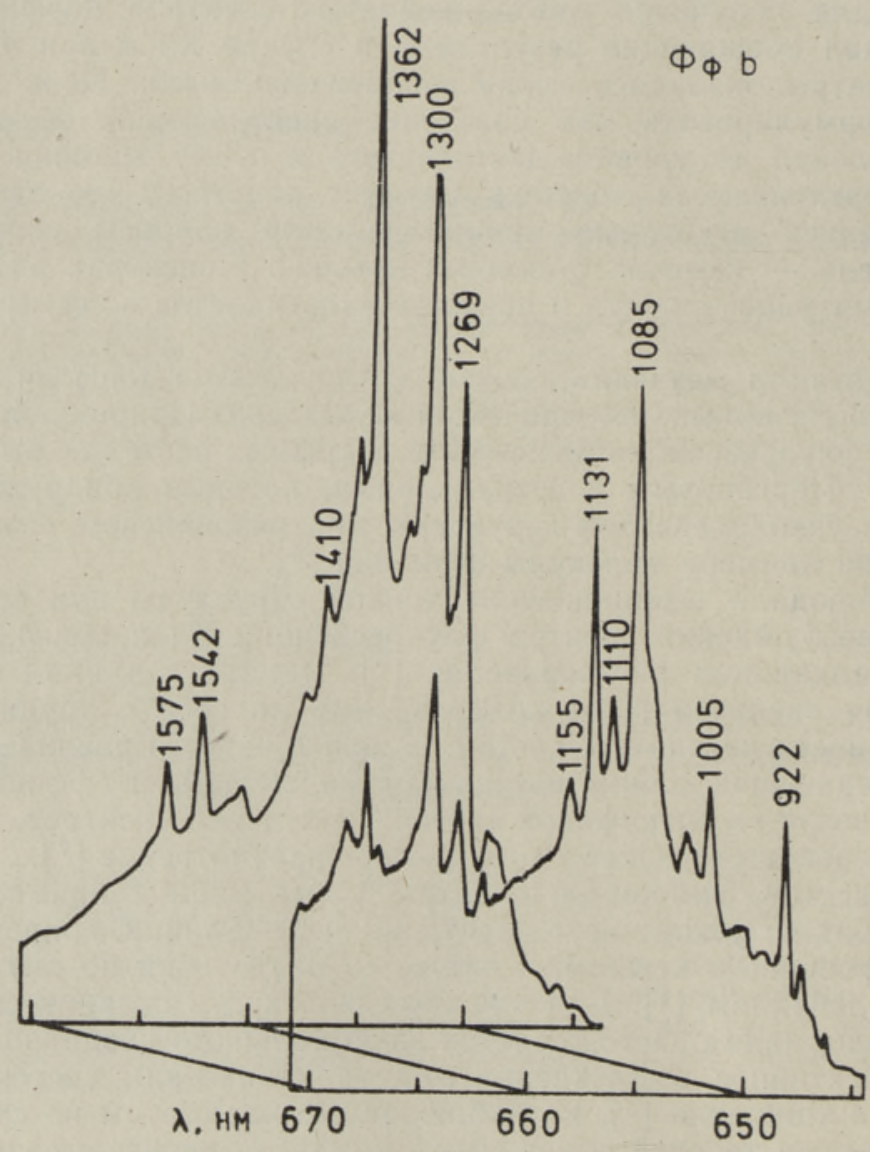

Рис. 1. Спектры флуоресценции феофитина $b$ в эфире при возбуждении лазером на красителе на длинах волн $\lambda_{e}=601$ (слева) и 612 нм (справа), $T=5 \mathrm{~K}$. 


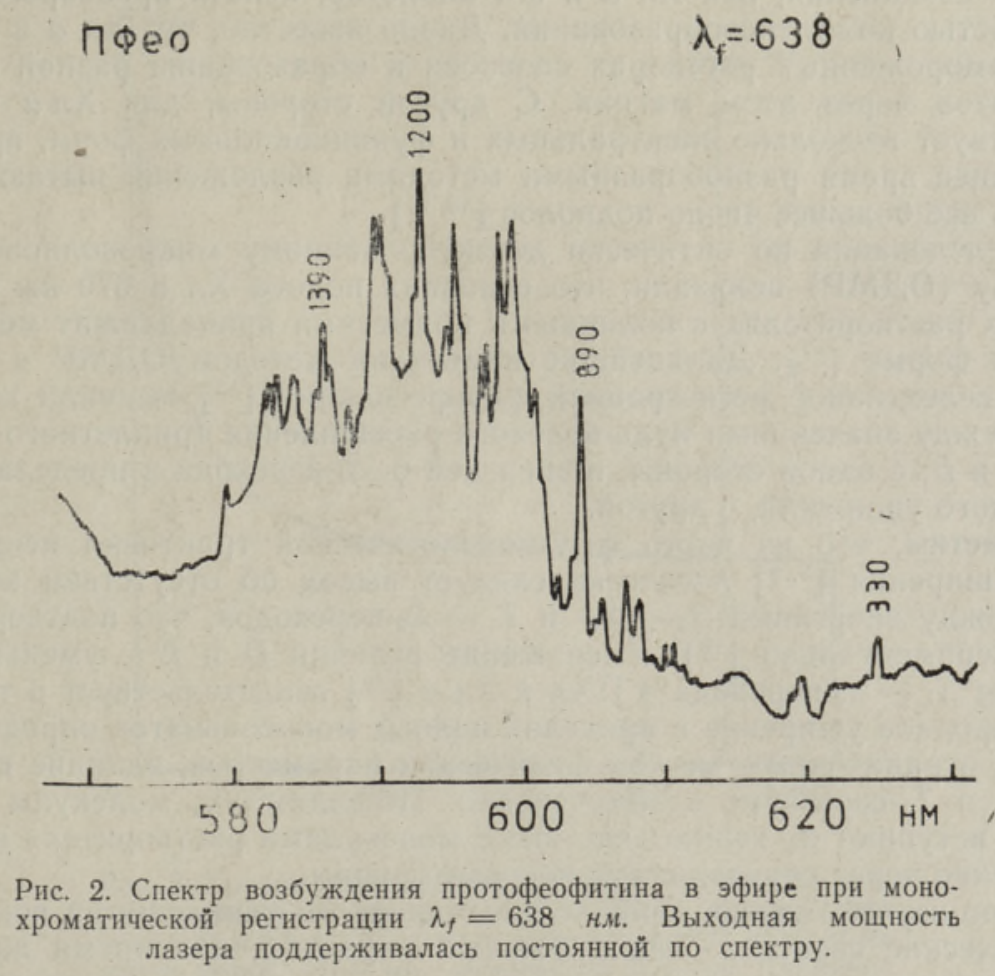

никновению богатой линейчатой структуры в $0-0$-полосе флуоресценции. Такие многолинейчатые спектры наблюдались как для Хл $a$, так и для его производных - феофитина $a(\Phi \phi a)$, Хл $b, \Phi \phi b$, протохлорофнлла (ПХл) и других $\left[{ }^{10-12}\right]$. В качестве матрицы можно использовать практически любой органический растворитель, но из соображений устойчивости пигментов для большинства измерений выбирался диэтиловый эфир. На рис. 1 для примера показаны спектры флуоресценции $Ф ф b$ в случае двух длин волн возбуждения. Около линий указаны частоты $\left(\mathrm{CM}^{-1}\right)$, определенные из спектра как расстояния до возбуждающей линии. Согласно реферируемым выше соображениям, они представляют собой колебательные частоты в возбужденном электронном состоянии $S_{1}$. Для ряда хлорофиллоподобных соединений мы получили таким путем наборы около 30 активных в вибронном переходе колебательных частот. Эти колебания проявляются непосредственно в спектрах возбуждения при монохроматической регистрации (рис. 2), которые весьма удобны для извлечения данных об относительных интенсивностях. Анализу колебательной структуры будет посвящена отдельная статья (предварительную интерпретацию см. в $\left[{ }^{12}\right]$ ).

В принципе, во всех спектрах флуоресценции (таких, как на рис. 1) присутствуют повторения 0-0-линий по частотам колебаний в основном электронном состоянии $S_{0}$. Но из-за наложения огромного числа слабых линий и их фононных крыльев эта область крайне неудобна для анализа. Более чистый спектр получается при резонансном $0-0$-возбуждении, однако оказалось, что.в этом случае происходит быстрое убывание линий по механизму фотохимического выжигания $\left[{ }^{13}\right]$. Частоты основного состояния хлорофиллов определялись также методами ИК-поглощения и комбинационного рассеяния $\left[{ }^{14}\right]$. Большинство частот $S_{1}$ - и $S_{0}$-состояния хорошо согласуются между собой.

Обсуждая вопросы, связанные с неоднородным уширением спектров 
такого соединения, как Хл $a$ и ёго аналогов, нёльзя пренебрегать возможностью комплексообразования. Давно известно, что Хл $a$ в жидких нли замороженных растворах способен к образованию разной степени сольватов через атом магния. С другой стороны, для Хл $a$ in vivo существует несколько спектральных и функциональных форм, причем в последнее время разнообразными методами разложения пытаются выделить все большее число подполос $\left[{ }^{15}, 16\right]$.

Исследования по оптически детектированному микроволновому резонансу (ОДМР) показали, что основная полоса Хл а 670 нм в неполярных растворителях с полярными примесями принадлежит моносольватной форме $\left[{ }^{17}\right]$. Дальнейшие измерения методом ОДМР в сочетании с селективной регистрацией флуоресценции $\left[{ }^{18}\right]$ выявили корреляцию между значениями нуль-полевого расщепления триплетного состояния $D$ и $E$, с одной стороны, и энергией $0-0$-перехода в пределах неоднородного уширения, с другой.

Отметим, что из чисто феноменологической трактовки неоднородного уширения $\left[{ }^{7,9}\right]$ логически следует вывод об отсутствии корреляции между энергиями $S_{1}-S_{0^{-}}$и $T_{1}-S_{0}$-переходов, что подтвердилось и экспериментально $\left[{ }^{19}\right]$. Уменьшение величин $D$ и $E$ с уменьшением частоты $S_{1}-S_{0}$-перехода в ПХл и Хл $a\left[{ }^{18}\right]$ свидетельствует о том, что неоднородное уширение в пределах полосы моносольватов определяется весьма ограниченным числом физических параметров, влияние которых на $S_{1-}$ и $T_{1}$-состояние взаимосвязано. По-видимому, молекулы хлорофилла вступают во взаимодействие с молекулами растворителя преимущественно через определенные боковые группы.

Было изучено также влияние неоднородного уширения на некоторые кинетические свойства. Такой важный параметр, как время жизни $\tau_{1}$ возбужденного электронного состояния Хл $a$, оказался зависящим от длины волны регистрации $\lambda_{f}$ в пределах неоднородной полосы $\left[{ }^{20}\right]$. При увеличении концентрации в значениях $\tau_{f}$ проявлялся перенос энергии вниз по контуру неоднородного уширения (см. также [ $\left.\left.{ }^{21}\right]\right)$.

Триплетные состояния ранее изучались такими методами, как флешфотолиз, ЭПР и др. Сравнительно недавно была обнаружена фосфоресценция хлорофиллов $\left[{ }^{22}\right]$, однако из-за ее слабости приходилось для исследования их $T_{1}$-состояния привлекать все новые методы. Выше уже упоминался один из них - ОДМР с регистрацией по флуоресценции. Нами разработана еще одна чисто оптическая методика - измерение временной зависимости интенсивности флуоресценции после включения прямоугольного возбуждающего импульса (т. н. метод флуоресцентного детектирования триплетного состояния) $\left[{ }^{23}\right]$. Лазерное возбуждение мощностью $\sim 10$ мBт достаточно для создания высокой стационарной заселенности $T_{1}$-состояния хлорофиллов. Приближение к стационарному состоянию отражается в падении интенсивности флуоресценции с заселением триплета (рис. 3). Этот метод имеет, ряд достоинств - можно ограничиться оптическими измерениями, исследовать микроколичества веществ, непосредственно определять заселенность триплетного состояния, а также другие параметры. Кроме того, этим способом обнаружена связь между $\lambda_{f}$ в неоднородной полосе флуоресценции и параметрами триплетного состояния $\left[{ }^{23}\right]$ - на коротковолновом краю спектра флуоресценции $\tau_{T}$ растет.

Таким образом, прослеживается весьма четкая зависимость ряда спектрально-кинетических параметров молекулы от энергии $S_{1}-S_{0}$-перехода для Хл $a$ и его аналогов в системах с неоднородным уширением. Эта зависимость гладкая, и нет необходимости вводить конечное число различных подмножеств молекул (т. н. спектральных форм). Этот вывод нельзя, конечно, непосредственно переносить на in vivo системы.

В результате сложения однородных ширин БФЛ как при возбужде- 


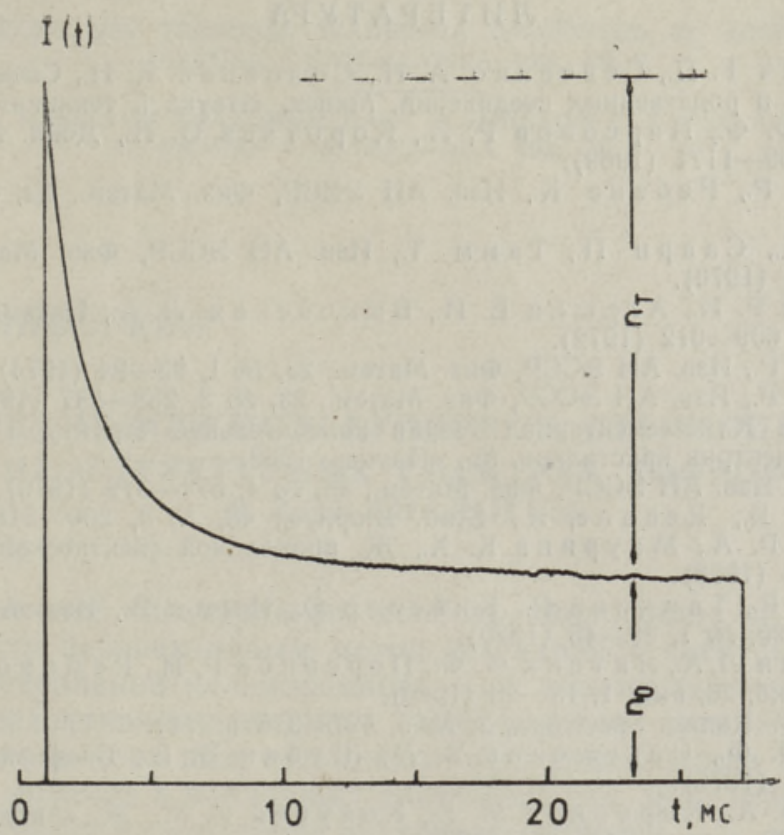

Рис. 3. Кривая спада интенсивности флуоресценции протохлорофилла в эфире при $T=77 \mathrm{~K}$. Возбуждение прямоугольными импульсами мощностью $200 \mathrm{MBT} / \mathrm{cm}^{2}$ на длине волны 441,6 нм, регистрация 625 нм. Показаны относительные заселенности триплетного $n_{T}$ и основного синглетного $n_{0}$ состояний.

нии в вибронной области, так и в $0-0$-полосе (с регистрацией на вибронных повторениях) наблюдаемая ширина определяется уширением колебательных подуровней, составляющим несколько $c M^{-1}$. Регистращии же строго резонансной флуоресценции препятствует наличие рассеянного света. Эта трудность была преодолена применением метода фотохимического выжигания провала, с помощью которого для Хл $a$ было достигнуто спектральное разрешение $\Delta v / v=1,5 \cdot 10^{6}$ (более подробно cм. $\left.\left[{ }^{24}\right]\right)$.

Не потеряли своей актуальности и стремления к получению тонкоструктурных спектров путем выбора специальных матриц-растворителей. Удалось показать, что вполне отчетливые спектры Шпольского можно получить для растворенных в н-алканах феофорбидов, т. е. хлорофиллов без магния и фитола $\left[{ }^{25}\right]$. Такие спектры имеют преимущество с аналитической точки зрения - данной молекуле в данном растворителе всегда соответствует определенный мультиплет, не зависящий от частоты неселективного возбуждения. Добавим, что избавление от примесей в количестве ниже $10^{-3}$ по отношению к основному пигменту - трудновыполнимая в случае хлорофиллоподобных молекул задача $\left[{ }^{26}\right]$.

В итоге можно констатировать, что за последние годы в спектроскопии хлорофиллоподобных молекул достигнуты определенные успехи - повышено спектральное разрешение и внедрены новые методы определения кинетических параметров.

В заключение выражаю глубокую благодарность К. К. Ребане за поддержку выбранного направления и за многократные обсуждения результатов. Я также благодарен К. Х. Маурингу, А. П. Суйсалу и Р. П. Тамкиви за участие в совместных исследованиях. 
1. Гу рин нович Г. П., Севченко А. Н., Соловьев К. Н., Спектроскопия хлорофилла и родственных соединений, Минск, «Наука и техника», 1968.

2. Л и тв и $Ф$. Ф., Пе р сонов Р. И., Корота ев О. Н., Докл. АН СССР, 188, № 5, 1169-1171 (1969).

3. А в а рм а а Р., Р еб ан е К., Изв. АН ЭССР, Физ. Матем., 22, № 1, 108-110 (1973).

4. Ребан К К., Са ари П., Т а мм Т., Изв. АН ЭССР, Физ. Матем., 19, № 2, $251-254$ (1970).

5. Персонов Р. И., Альшиц Е. И., Быковская Л. А., Письма в ЖЭТФ, 15, вып. 10, 609-612 (1972).

6. А в а р м а а Р., Изв. АН ЭССР, Физ. Матем., 23, № 1, 93-94 (1974).

7. А в а р м а а Р., Изв. АН ЭССР, Физ. Матем., 23, № 3, 238-247 (1974).

8. Р ебане К. К., Элементарная теория колебательной структуры спектров примесных центров кристаллов, М., «Наука», 1968.

9. Ки к а с Я., Изв. АН ЭССР, Физ. Матем., 25, № 4, 374-379 (1976).

10. Avarmaa, R., Rebane, K., Stud. Biophys., 48, № 3, 209-218 (1975).

11. А в а р м а Р. А., М а ури нг К. Х., Ж. прикладной спектроскопин, 28, вып. 4, 658-662 (1978).

12. А в а рм а а Р., Т а м ки ви Р., Ки йсл е р С., Ным м В., Изв. АН ЭССР, Физ. Матем., 29, № 1, 39-45 (1980).

13. Быковская Л.А., Литвин $Ф$. Ф., Персонов Р. И., Романовский Ю. В., Биофизика, 25, вып. 1, 13-20 (1980).

14. L u t z, M., J. Raman Spectrosc., 2, № 5, 497-516 (1974).

15. Литвин $\Phi$. Ф., Синещеков В. А.; Шубин В. В., Биофизика, 21 , вып. 4 , 669-675 (1976).

16. Гули ев Ф. А., Коробков М. Е., Кочу бей С. М., Ж. прикладной спектроскопии, 29, вып. 4, 646-651 (1978).

17. Koo yman, R. P. H., S cha af sma, T. J., Kleibeuker, J. F., Photochem. Photobiol., 26, № 3, 235-240 (1977).

18. Avarmaa, R., Scha a f ma, T. J., Chem. Phys. Lett., 71, № 2, 339-344 (1980).

19. С а а р и П. М., Т а м м Т. Б., Изв. АН СССР, сер. физ., 39, № 11, 2321-2325 (1975).

20. Т а м ки в и Р. П., А в а р м а а Р. А., Изв. АН СССР, сер. физ., 42, № 3, 568-572 (1978).

21. Т а м к и в и Р. П. (см. настоящий номер).

22. К ра сновский А. А., Литвин Ф. Ф., Изв. АН СССР, сер. физ., 39 , № 9 , 1968-1971 (1975).

23. Ava rm a a, R., Chem. Phys. Lett., 46, № 2, 279-282 (1977); Mol. Phys., 37, № 2, 441-454 (1979).

24. М а у инн К. Х., Ав а рм а а Р. А. (см. настоящнй номер).

25. Ав а р м а а Р., Т а мки ви Р., Изв. АН ЭССР, Физ. Матем., 29, № 4, 442-444 (1980).

26. Тын и ссоо В., Т а мк и ви Р., Изв. АН ЭССР, Хим., 27, № 4, 219-223 (1978).

\section{Институт физики \\ Академии наук Эстонской ССР}

\section{R. A. AVARMAA}

\section{KLOROFOLLI JA TA DERIVAATIDE LUMINESTSENTSI PEENSTRUKTUURSED SPEKTRID JA KINEETIKA}

On antud ülevaade klorofüllisarnaste molekulide peenstruktuursetest spektritest selektiivsel laserergastusel ja sellega seotud kineetilistest mōōtmistest.

\section{R. A. AVARMAA}

\section{FINE-STRUCTURE SPECTRA AND KINETICS OF LUMINESCENCE OF CHLOROPHYLL AND ITS DERIVATIVES}

A review is given on the fine-structure spectra of chlorophyll-like molecules under selective laser excitation, as well as on the related kinetic measurements. 